\title{
REAPROVEITAMENTO DA CINZA DE CASCA DE ARROZ NA CONSTRUÇÃO CIVIL
}

\section{REUSE OF RICE HUSK ASH IN BUILDING CONSTRUCTIONS}

\section{Mauro Mitsuuchi Tashima ${ }^{1}$, Leandro Cirqueira Sousa ${ }^{2}$, Jorge Luis Akasaki ${ }^{3}$, Everton Jose da Silva ${ }^{4}$, José Luiz Pinheiro Melges $^{5}$, Jorge Juán Payá Bernabeu ${ }^{6}$}

${ }^{1}$ Doutorando, Departamento de Ingeniería de la Construcción y de Proyectos de Ingeniería Civil, Instituto de Ciencia y Tecnología del Hormigón, Universidad Politécnica de Valencia - UPV, España, e-mail: tashima@japan.com ${ }^{2}$ Aluno de Graduação e Bolsista FAPESP, Departamento de Engenharia Civil, Universidade Estadual Paulista - UNESP - Campus de Ilha Solteira, e-mail: 1sousa.eng@gmail.com

${ }^{3}$ Professor Adjunto, Departamento de Engenharia Civil, Universidade Estadual Paulista - UNESP - Campus de Ilha Solteira, e-mail: akasaki@dec.feis.unesp.br ${ }^{4}$ Professor, Instituto Federal de Educação, Ciência e Tecnologia da Bahia, IFBA, Brasil. e-mail: everton-js@hotmail.com

${ }^{5}$ Professor Doutor, Departamento de Engenharia Civil, Universidade Estadual Paulista - UNESP - Campus de Ilha Solteira e-mail: jlmelges@dec.feis.unesp.br ${ }^{6}$ Catedrático, Departamento de Ingeniería de la Construcción y de Proyectos de Ingeniería Civil, Instituto de Ciencia y Tecnología del Hormigón, Universidad Politécnica de Valencia - UPV, España, e-mail: jipaya@cst.upv.es Alameda Bahia, 550 - Centro - 15385-000 - Ilha Solteira - SP - Fone: (18) 37431213.

\section{RESUMO}

O crescimento da população mundial, associado ao avanço tecnológico alcançado nos últimos anos, gera como consequência uma enorme contaminação meio ambiental, tanto no que se refere à emissão de gases tóxicos, quanto na produção de enormes quantidades de resíduos, sem um local apropriado para a sua disposição final. Entre os resíduos agrícolas, pode-se destacar a imensa quantidade de cinza de casca de arroz, produzida pela indústria do arroz. Uma das soluções para evitar esses problemas é a reutilização da cinza de casca do arroz em outros setores produtivos, por exemplo, construção civil. O presente trabalho apresenta uma breve revisão sobre as pesquisas que vêm sendo desenvolvidas em termos de reaproveitamento da cinza de casca de arroz na construção civil, mais especificamente, em concretos e argamassas.

Palavras-chave: Cinza de casca de arroz. Construção civil. Impactos ambientais. 


\begin{abstract}
The world population growth, coupled with technological advances achieved in recent years, generates high environmental contamination, both as associated with the greenhouse gas emission, as the high waste production without an appropriate place for its final disposal. Among the agricultural wastes, it can highlight the high amount of rice husk ash that is produced by the rice industry. One solution to avoid these problems is the reuse of rice husk ash in other sectors, such as building construction. This paper presents a brief review of the research that has being carried out in terms of reuse of rice husk ash in construction, more specifically, in concrete and mortar preparation.
\end{abstract}

Keywords: Rice husk ash. Building construction. Environmental impacts.

\title{
1. INTRODUÇÃO
}

Atualmente, pode-se observar que os avanços científicos e tecnológicos são elementos fundamentais para se alcançar o desenvolvimento de uma sociedade, entretanto, estes podem vir acompanhados de problemas de ordem ambiental.

Os processos agrícolas e industriais, além de gerar enorme quantidade de resíduos, também são responsáveis por um grande consumo de energia e de matéria-prima não renovável. $\mathrm{O}$ reaproveitamento desses resíduos agrícolas e industriais, como subprodutos ou incluso como matéria-prima em outros setores produtivos, aparece como questão fundamental na conservação do meio ambiente.

Essa preocupação ambientalista deu origem à chamada era ecológica que provocou o surgimento de uma legislação ambiental mais rigorosa, obrigando o gerador de resíduos a dispô-los de maneira adequada sem agredir o meio ambiente. Entre esses resíduos, podem-se mencionar os resíduos de construção e demolição, da indústria siderúrgica, agrícolas e outros. Neste trabalho destaca-se especialmente a cinza de casca de arroz, resíduo agrícola proveniente da combustão da casca do arroz.

\section{A CASCA DE ARROZ E SUAS APLICAÇÕES}

Para se ter uma idéia da quantidade de casca de arroz gerada anualmente, deve-se ter em consideração a produção mundial de arroz: aproximadamente 600 milhões de toneladas de arroz em casca. Levando em consideração que cerca de $20 \%$ dessa produção é casca, é obtido um total de 120 milhões de toneladas de casca de arroz por ano.

O Brasil, considerado um dos dez maiores produtores de arroz do Mundo, produziu em 2010, cerca de 11,3 milhões de toneladas de arroz em casca (IBGE, 2010), sendo a região sul do país responsável pela maior parte dessa produção. A casca de arroz, como não possui nenhuma destinação específica, pode ser aplicada para diversos fins. A Figura 1 mostra algumas das aplicações que vêm sendo dadas para a casca de arroz. 


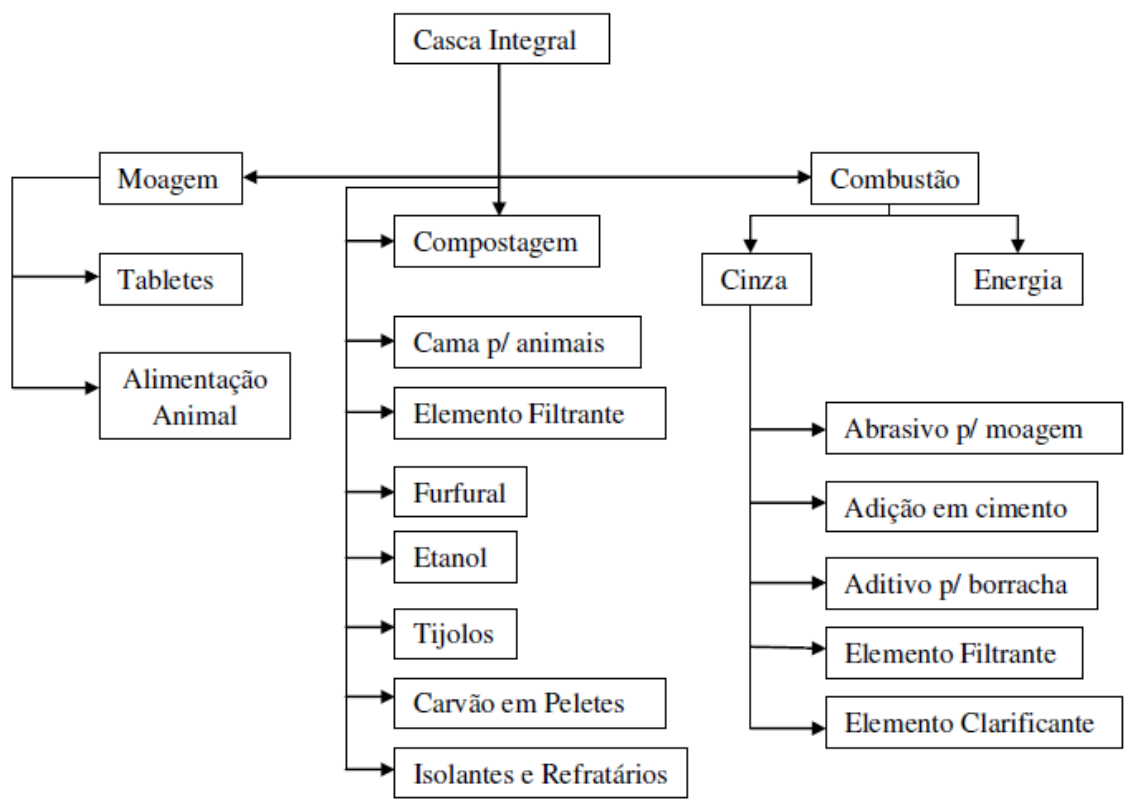

Figura 1. Principais aplicações para a casca de arroz (SILVA, 2009).

A principal aplicação para a casca de arroz, entretanto, é a geração de energia para o processo de secagem e parboilização dos grãos de arroz. Isso se deve ao elevado poder calorífico do material, que segundo Diniz et al. (2004), é de aproximadamente $16,33 \mathrm{MJ} / \mathrm{kg}$, constituindo assim, uma fonte alternativa para a produção de energia. Como resultado desse processo, porém, grande quantidade de cinza é produzida e comumente descartada de forma inadequada, gerando uma grande preocupação quanto aos problemas ambientais que surgem diante do fato de se tratar de um resíduo poluidor. As Figuras 2 e 3 ilustram a forma como vêm sendo descartada a cinza de casca de arroz, nas margens de rodovias, de riachos e em terrenos baldios.

Figura 2. Descarte inadequado da cinza de casca de arroz nas margens de rodovias (SANTOS, 1997). 

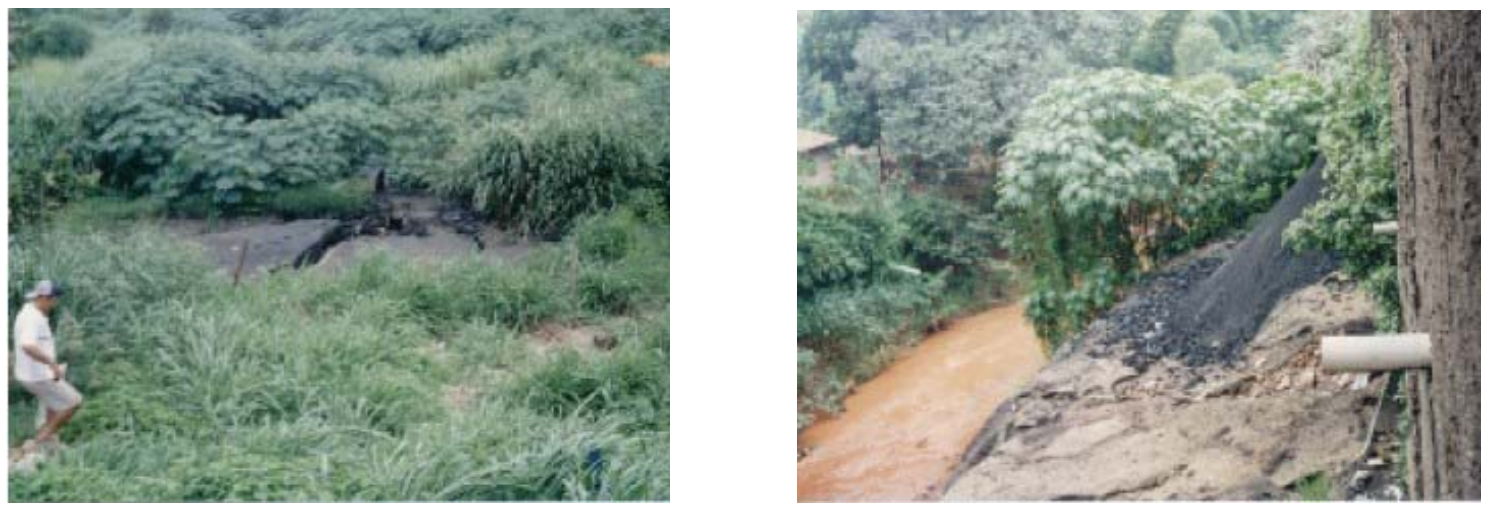

Figura 3. Deposição da cinza de casca de arroz em terrenos baldios e nas margens de um riacho (RÊGO, 2001).

$\mathrm{Na}$ maior parte dos países produtores de arroz, diversos estudos estão sendo realizados no sentido de aumentar as possibilidades de reutilização da Cinza de Casca de Arroz (CCA) em outros setores produtivos. Neste sentido, a construção civil está utilizando a CCA como material pozolânico na preparação de concretos e argamassas a base de cimento Portland.

\section{MATERIAIS POZOLÂNICOS}

A utilização de argamassas e concretos na construção civil é uma prática comum no Mundo inteiro, sendo que a utilização deste material está associada a sua elevada resistência mecânica, a sua facilidade de preparação e moldagem e, principalmente, devido ao baixo custo do material. Como dado complementar, se pode dizer que o concreto é o segundo material mais consumido no Mundo, sendo superado somente pela água (AITCIN, 2000).

Normalmente, a utilização de argamassas e concretos está associada ao uso do cimento Portland. A produção de cimento, porém, é responsável por enorme degradação do meio ambiente, tanto no que se refere ao consumo de energia e de matérias-primas não renováveis como devido à elevada emissão de gases tóxicos, que contribuem com a formação do efeito estufa.

Diante dessa situação e, levando em consideração a pontecialidade de aplicação dos resíduos agrícolas e industriais em outros setores produtivos, diversos esforços estão sendo realizados no sentido de utilizar estes resíduos como, material pozolânico na preparação de argamassas e concretos.

Segundo a Associação Brasileira de Normas Técnicas, por meio da NBR 12653, as pozolanas são materiais silicosos ou silicoaluminosos que, por si só, possuem pouca ou nenhuma atividade aglomerante, mas que, quando finamente divididos e na presença da água, reagem com o hidróxido de cálcio, à temperatura ambiente para formar compostos com propriedades cimentantes, similares aos produtos gerados na hidratação do cimento Portland. (ABNT, 1992).

Cabe destacar que durante o processo de hidratação do cimento, são formados produtos cimentantes caracterizados como gel do tipo C-S-H ou C-A-S-H. Além disso, também se liberam durante a hidratação, aproximadamente um $20 \%$ de hidróxido de cálcio. É com esse hidróxido de cálcio que as pozolanas reagem para formar novos produtos cimentantes, e por tanto, aumentar as propriedades mecânicas e de durabilidade das argamassas e concretos.

A reação pozolânica pode ser descrita de forma simplificada através da seguinte equação:

$$
\mathrm{xSiO}_{2}+\mathrm{yCaO}+\mathrm{zH}_{2} \mathrm{O} \rightarrow \mathrm{yCaO} \cdot \mathrm{xSiO} \mathrm{SiH}_{2} \mathrm{O}
$$


Como se pode observar, o produto formado pela reação pozolânica (C-S-H) é bastante similar aos produtos formados durante a hidratação do cimento, podendo ser diferenciados pela relação $\mathrm{Si} / \mathrm{Ca}$.

Para que aconteça o processo de reação pozolânica, é necessário que a adição mineral em questão apresente uma elevada finura, grandes quantidades de $\mathrm{SiO}_{2}+\mathrm{Al}_{2} \mathrm{O}_{3}$ na sua composição, além de apresentar uma mineralogia amorfa. $\mathrm{O}$ conjunto dessas características faz com que essa adição mineral possa ser considerada pozolânica desde o ponto de vista cimentante.

\section{A CCA NA CONSTRUÇÃO CIVIL}

O processo de utilização de cinza de casca de arroz em concretos e argamassas iniciou-se na década de 70, onde Mehta e Pitt (1976) utilizavam um processo controlado de queima da casca para obter cinzas de excelentes características.

As diversas pesquisas realizadas com a cinza de casca de arroz mostram que este resíduo pode ser utilizado em substituição parcial ao cimento Portland, na preparação de aglomerantes cimentantes melhorando as propriedades finais do produto formado. Não se pode esquecer, entretanto, que as propriedades alcançadas pelas argamassas e concretos produzidos com a CCA, dependem das características físicas, químicas e mineralógicas da mesma.

Para que a CCA se apresente em um estado amorfo, ou seja, com uma estrutura desordenada, é necessário que o processo de combustão da cinza não ultrapasse a temperatura de $600{ }^{\circ} \mathrm{C}$ (PAYÁ et al., 2001). Seguindo essa mesma linha de raciocínio, os autores ainda afirmam que no caso de temperatura de queima da CCA é baixa (abaixo de $600{ }^{\circ} \mathrm{C}$ ) e quando o tempo de queima é pequeno (em torno de 6 horas), a sílica contida na cinza é predominantemente amorfa. Ou seja, quanto menos tempo a cinza ficar exposta a uma elevada temperatura, menos cristalização ocorre. A presença de fases cristalinas na cinza pode ser identificada por meio do equipamento de difração de raios- $X$, o qual faz uma análise qualitativa da presença ou não dessas fases, podendo inclusive identificar as fases cristalinas existente.

Outro fator que se deve levar em conta é a presença de carbono residual. Segundo Maeda et al. (2001), as cinzas cujo carbono residual, determinado pelo ensaio de perda ao fogo, são inferiores a 3\%, são consideradas com baixo teor de carbono. O uso de cinzas com elevadas porcentagens de carbono na sua composição, entretanto, podem apresentar problemas associados à demanda de água excessiva, prejudicando as propriedades finais do aglomerante formado.

Estudos realizados por Pereira (2003) mostram que a adição da cinza de casca de arroz contribui de forma significativa nos estudos de carbonatação e penetração de íons cloretos. Para 0 caso dos íons cloretos observaram reduções de 79\% em relação ao traço de referência.

Uma das aplicações dadas para a CCA foi a sua utilização na preparação de tijolos de solocal e solo-cimento (MILANI e FREIRE, 2006). Os resultados mostram que a casca de arroz apresenta-se como um material alternativo promissor, já que, além de racionalizar o uso da terra, minimiza o descarte da casca de arroz em condições e locais inadequados.

Estudos realizados por Silva (2004) utilizando CCA em concretos e argamassas mostram aumentos significativos na resistência à compressão, para dosagens de 5 e $10 \%$ de CCA. Aos 28 dias, obteve-se ganhos de resistência de até $24 \%$ para o concreto e de $28 \%$ em argamassas.

Akasaki et al. (2005) citaram que a incorporação de cinza de casca de arroz na confecção de argamassas e concretos não prejudica propriedades importantes para a funcionalidade de execução tais como: tempos de início e fim de pega, expansibilidade e retração por secagem. De acordo com Duart et al. (2006) a cinza de casca de arroz sem moagem pode ser utilizada em concretos, desde que o tempo de mistura do concreto seja estudado. 
Tashima (2006) realizou caracterização físico-química da CCA produzida pelo grupo de pesquisa MAC - Materiais Alternativos de Construção da UNESP - Ilha Solteira. A CCA estudada apresentou-se altamente reativa, sendo que $99 \%$ da sílica encontravam-se em estado amorfo. Os resultados de resistência à compressão de argamassas mostram ganhos superiores a 40\% quando comparados com o traço controle. Ainda neste mesmo trabalho, concluiu que a CCA em estudo pode ser utilizada com uma fonte alternativa da sílica ativa, devido a suas excelentes características.

De acordo com Silva (2007), a utilização da CCA interfere na trabalhabilidade das misturas, já que se trata de um material extremamente fino e, portanto, com uma absorção de água elevada. Por isso, o uso da CCA vem, quase que sempre, associado ao uso de aditivos superplastificantes na produção de concretos e argamassas. Segundo Tashima (2006), no estado fresco pode-se observar maior coesão e menor exsudação da mistura, já no estado endurecido o que se verifica é um incremento na resistência à compressão, uma diminuição na permeabilidade e, um aumento na durabilidade do concreto.

De acordo com Meira et al. (2007), que estudaram as propriedades do concreto com cinza de casca de arroz sem queima controlada e sem moagem; os ensaios realizados nos corpos de prova com $15 \%$ e $25 \%$ de substituição de cimento por CCA moída e com $15 \%$ de substituição de cimento por CCA natural apresentaram acréscimos nas resistências axiais aos 91 dias em relação aos concretos de referência (sem adição mineral). Essa melhoria é devida à ação pozolânica da cinza de casca de arroz e também devido ao efeito filler do material. O efeito filler é o preenchimento de vazios do concreto utilizando partículas menores. Isso faz com que diminua a quantidade de poros existentes e melhore a coesão da matriz de cimento.

Já Hoppe (2008) concluiu que é possível obter concretos melhores utilizando CCA em seu estado físico natural, sem moagem. O diferencial de sua pesquisa é que esse autor utilizou uma ordem de colocação de materiais na betoneira diferenciada. Ele fez com que o aglomerante utilizado em substituição parcial do cimento fosse misturado junto com o agregado graúdo, antes da colocação de cimento e aditivo diminuindo assim o tamanho das partículas da cinza.

Habeeb e Mahmud (2010) confeccionaram concretos com CCAs em diferentes granulometria, nas proporções de $5 \%, 10 \%, 15 \%$ e $20 \%$ em substituição ao cimento e com diferentes teores de aditivo superplastificante para manter a mesma consistência. Esses autores concluíram que os concretos com 10\% de substituição e com diâmetro médio das partículas de 11,5 $\mu \mathrm{m}$ obtiveram os melhores resultados de resistência à compressão, obtendo resultados superiores ao traço controle desde a idade de um dia até 28 dias.

Isaia et al. (2010), utilizando técnica semelhante à utilizada por Hoppe (2008), concluíram que existe viabilidade de utilização de $15 \%$ de CCA natural (sem moagem) em substituição ao cimento, em concreto para fins estruturais. Os desempenhos para esse teor são inferiores àqueles das misturas com CCA (com moagem) ou REF (sem adições), há 28 dias, entretanto ainda dentro de parâmetros considerados adequados para estruturas convencionais.

Com relação à perda de massa, Metha e Folliard (2001), constataram que ao expor corpos de prova de concreto com adição de CCA ao ataque de ácido clorídrico por diversas semanas, estes apresentaram perda de massa significativamente inferior ao concreto de referência, não atingindo o limite de $25 \%$ de perda de massa em 28 semanas. Já o concreto de referência atingiu esse limite em 11 semanas e chegou a quase $70 \%$ de perda de massa há 28 semanas. Os autores também mostram em seu estudo a menor expansão da argamassa com adição de CCA. Comparada à argamassa sem adição, a redução foi de $82 \%$ na $16^{\circ}$ semana.

Habeeb et al. (2010) avaliaram o ataque de sulfato de magnésio em concretos contendo CCA ( $20 \%$ de substituição em relação ao cimento) com diversos tamanhos de partículas. Os resultados mostraram que as amostra expostas ao sulfato exibiram maior resistência e módulo dinâmico de elasticidade do que as amostras mantidas em água, porém sofreram perda de massa e fragmentação 
da superfície, sendo que os concretos com CCA fina resultaram em melhor resistência do que o concreto controle (sem CCA), comprovando assim, a maior durabilidade de concretos com CCA.

\section{CONCLUSÕES}

O presente trabalho mostrou que a utilização da cinza de casca de arroz na construção civil é uma grande oportunidade de minimização de problemas ambientais gerados pela disposição inadequada deste resíduo, além de contribuir para melhora de algumas propriedades de concretos e argamassas.

As pesquisas têm mostrado que a utilização da CCA pode contribuir de forma significativa tanto no que se refere a resistência à compressão quanto nos aspectos de durabilidade de concretos. Vale ressaltar que a melhora nessas propriedades depende principalmente da presença ou não de fases cristalinas e da finura da cinza.

Diante do exposto, observa-se um amplo campo de pesquisa e de aplicação para a cinza de casca de arroz na construção civil, especialmente em concretos e argamassas. A oportunidade de redução dos impactos ambientais é fortalecida pelo fato do concreto ser o segundo material mais consumido no mundo e, dessa forma poder absorver a enorme quantidade deste subproduto da agroindústria gerado todos os anos.

\section{AGRADECIMENTOS}

Os autores agradecem as agências de fomento CAPES, CNPq, FAPESP e ICITECH Instituto de Ciencia y Tecnología del Hormigón da UPV - Universidad Politécnica de Valencia Espanha, pelo apoio financeiro e científico para a realização das pesquisas do Grupo MAC Materiais Alternativos de Construção da UNESP - Campus de Ilha Solteira.

\section{REFERÊNCIAS}

\section{ABNT - ASSOCIAÇÃO BRASILEIRA DE NORMAS TÉCNICAS. NBR 12653: Materiais} Pozolânicos - Especificação. Rio de Janeiro, 1992.

AITCIN P. C. Cements of yesterday and today Concrete of tomorrow. Cement and Concrete Research, v. 30, Issue 9, p. 1349-1359, 2000.

AKASAKI, J. L.; SILVA, E. J.; TASHIMA, M. M.; BARBOSA, M. B.. Influência da adição de cinza de casca de arroz nos tempos de pega e retração por secagem. In: Simpósio Ibero-Americano, 2005, Coimbra - Portugal. Anais... Portugal: SIABE 05, 2005. p. 25-32.

DINIZ, J; CARDOSO, A. L.; STAHL, J. A.; VILLETTI, M. A., MARTINS, A. F. Poder calorífico da casca de arroz, caroço de pêssego, serragem de eucalipto e de seus produtos de pirólise. Ciência e Natura, Santa Maria, Rio Grande do Sul, v. 26, n. 2, p.25-32, 2004.

DUART, M. A.; ISAIA, G. C.; GASTALDINI, A.L.G.; CERVO, T.C.; HOPPE, A. E.; PEDROSO, E.C. Concretos convencionais com adição de cinza de casca de arroz sem controle de queima e sem moagem como substituto parcial do cimento. In: $48^{\circ}$ Congresso Brasileiro do Concreto, 2006, Rio de Janeiro. Anais... Rio de Janeiro: IBRACON, 2006. 
HABEEB, G. A.; MAHMUD, H. B.; HAMID, N. B. A. A. Assessment of deterioration in RHAconcrete due to magnesium sulphate attack. International Journal of Minerals, Metallurgy and Materials, v. 17, n. 6, p. 691-696, 2010.

HABEEB, G.; MAHMUD, H. B. Study on properties of rice husk ash and its use as cement replacement material. Materials Research, São Carlos, v.13, n.2, Junho 2010.

DOI:10.1590/S1516-14392010000200011. Disponível em: <http://www.scielo.br/ scielo.php?script =sci_arttext\&pid=S151 6-14392010000200011\&lng=en\&nrm=iso $>$. Acesso em: 15 Nov. 2010.

HOPPE, A. E. Carbonatação em concreto com cinza de casca de arroz sem moagem. 2008. 147f. Dissertação (Mestrado em Engenharia Civil) - Curso de Pós-Graduação em Engenharia Civil, Universidade Federal de Santa Maria, Santa Maria, 2008.

\section{IBGE - INSTITUTO BRASILEIRO DE GEOGRAFIA E ESTATÍSTICA. Indicadores} conjunturais: produção agrícola. Brasília: IBGE, 2010. Disponível em:

$<$ http://www.ibge.gov.br/home/estatistica/indicadores/agropecuaria/lspa/default.shtm $>$. Acesso em: 20 Mar. 2011.

ISAIA, G., GUERRA GASTALDINI, A., MEIRA, L., DUART, M., ZERBINO, R.. Viabilidade do emprego de cinza de casca de arroz natural em concreto estrutural. Parte I: propriedades mecânicas e microestrutura. Ambiente Construído, América do Norte, 10, jan. 2010. Disponível em:

$<$ http://www.seer.ufrgs.br/index.php/ambienteconstruido /article/view/9473/7439>. Acesso em: 25 Abril 2010.

MAEDA, N., WADA, I., KAWAKAMI, M., UEDA, T. Development of a New Furnace for the Production of Rice Husk Ash. In: MALHOTRA, V.M. (ed) 7th International Conference on Fly Ash, Silica Fume, Slag and Natural Pozzolans. Proceedings. American Concrete Institute. Detroit, 2001, v. 2, p.835-852.

MEHTA, P. K., FOLLIARD, K. J., Rice husk ash - A unique supplementary cementing material: durability aspects. In: Second ACI/CANMET International Symposium on Advances in Concrete Technology, Las Vegas, United State of America, p. 531-541, 2001.

MEHTA, P. K., PITT, N. Energy and industrial materials from crop residues. Resource Recovery and Conservation, v. 2, n. 1, p. 23-28, 1976.

MEIRA, L. R. ISAIA, G. C.; GASTALDINI, A. L. G.; CERVO, T. C.; SENSALE, G. R.; ZERBINO, R.; DIESEL, F. B. Propriedades mecânicas do concreto com cinza de casca de arroz sem queima controlada e sem moagem. In: $49^{\circ}$ CONGRESSO BRASILEIRO DO CONCRETO, 2007, Bento Gonçalves. Anais... Bento Gonçalves: IBRACON, 2007. 11p.

MILANI, A P. S.; FREIRE, W. J. Physical and mechanical characteristics of soil-cement and rice husk mixtures. Engenharia Agrícola, Jaboticabal, v.26, n.1, Apr. 2006.

PAYÁ, J.; MONZÓ, J.; BORRACHERO, M. V.; MELLADO, A.; ORDOÑEZ, L. M. Determination of amorphous silica in rice husk ash by a rapid analytical method. Cement and Concrete Research, v. 31, n. 2, p. 227-231, 2001. 
PEREIRA, A. C. Influência das Adições Minerais na Durabilidade do Concreto Sujeito à Carbonatação. 2003. 215 f. Dissertação (Mestrado em Engenharia Civil) - Escola de Engenharia Civil, Universidade Federal de Goiás, Goiânia, 2003.

RÊGO, J. H. S. Viabilidade Técnica da Utilização da Cinza de Casca de arroz produzida sem controle da temperatura como adição mineral ao cimento. 2001. 199 f. Dissertação (Mestrado em Engenharia Civil) - Escola de Engenharia Civil, Universidade Federal de Goiás, Goiânia, 2001.

SANTOS, S. Estudo da viabilidade de utilização de cinza de casca de arroz residual em argamassas e concretos. 1997. 133 f. Dissertação (Mestrado em Engenharia Civil) - Universidade Federal de Santa Catarina, Florianópolis, 1997.

SILVA, E. J. Contribuição para utilização de cinza de casca de arroz na construção civil. 2009. 117 f. Dissertação (Mestrado em Engenharia Civil) - Universidade Estadual Paulista "Júlio de Mesquita Filho", Ilha Solteira, 2009.

SILVA, C. A. R. Aplicação do Conceito de Maturidade em concretos com adição da cinza de casca de arroz. 2004. 115 f. Dissertação (Mestrado em Engenharia Civil) - Universidade Estadual Paulista "Júlio de Mesquita Filho", Ilha Solteira, 2004.

SILVA, I. O. Influência da cinza de casca de arroz amorfa e cristalina e da sílica ativa na reação álcali-agregado. 2007. 125 f. Dissertação (Mestrado em Engenharia Civil) - Escola de Engenharia Civil, Universidade Federal de Goiás, Goiânia, 2007.

TASHIMA, M. M. Cinza de casca de arroz altamente reativa: método de produção, caracterização físico-química e comportamento em matrizes de cimento portland. $2006.81 \mathrm{f}$. Dissertação (Mestrado em Engenharia Civil) - Universidade Estadual Paulista "Júlio de Mesquita Filho", Ilha Solteira, 2006. 